flow of heat and matter in the interior ${ }^{2}$. This flow, in turn, drives the tectonic evolution of the surface, including the occurrence of volcanism and seismicity.

Olivine, a solid solution of forsterite $\left(\mathrm{Mg}_{2} \mathrm{SiO}_{4}\right)$ and fayalite $\left(\mathrm{Fe}_{2} \mathrm{SiO}_{4}\right)$, has the approximate composition $\left(\mathrm{Mg}_{0.89} \mathrm{Fe}_{0.11}\right)_{2} \mathrm{SiO}_{4}$ (called forsterite-89 or Fo89) in samples from the shallow mantle. It transforms from the olivine $(\alpha)$ phase to wadsleyite $(\beta)$, changing again to ringwoodite $(\gamma)$ at greater depths and eventually breaking down to a mixture of silicate perovskite and magnesiowüstite. In standard compositional models of the upper mantle such as the pyrolite ${ }^{3}$ model, in which a mix of different minerals is taken to account for the rocks and melts erupted at the surface from the interior, olivine accounts for only about $60 \%$ of the mantle by volume. Other minerals concerned include orthopyroxene, clinopyroxene and garnet, which gradually dissolve each into the next with increasing depth. Despite a pioneering study nearly 20 years ago, in which Akaogi and Akimoto ${ }^{4}$ pointed out that knowledge of element partitioning amongst these minerals is indispensable' for understanding the mantle, to this day the olivine polymorphs are treated in isolation from pyroxenes and garnets in most models of the mantle.
Irifune and Isshiki ${ }^{1}$ have shown such artificial separation to be misleading by experimentally demonstrating $\mathrm{Mg}-\mathrm{Fe}$ exchange between $\alpha, \beta$, garnet and clinopyroxene. We have known ${ }^{5}$ for some time that the proportions of these minerals vary with depth, as shown by the bold white lines in Fig. 1, but Irifune and Isshiki have now measured the accompanying variations in the compositions of coexisting minerals, shown by the colours. In isolated Fo89 olivine, mineral compositions must remain constant, except in the narrow zone of $\alpha-\beta$ coexistence. In pyrolite, however, all phases grow increasingly Mg-rich with depth. Given that bulk composition is fixed, this entails an increasing abundance of the most Fe-rich phase, garnet. Indeed, gradual dissolution of the less Fe-rich pyroxenes into the garnet both raises the proportion of garnet and dilutes the garnet to lower $\mathrm{Fe}$ levels. However, given constant $\mathrm{Mg}-\mathrm{Fe}$ partitioning ratios (incidentally confirmed by Irifune and Isshiki), such dilution drives Fe-depletion (that is, Mg-enrichment) of $\alpha$ to maintain equilibrium levels of $\mathrm{Fe}$ in garnet. As a result, olivine above the $\alpha-\beta$ transition in pyrolite becomes enriched in $\mathrm{Mg}$ relative to that in Fo89.

Such Mg-enrichment of $\alpha$ shifts the $\alpha-\beta$ transition to higher pressures (as can be seen in Irifune and Isshiki's Fig. 3 on page 704), so the onset of the transition in pyrolite is postponed to greater depths relative to that in Fo89. On the other side of the phase change, $\beta$ does not partition $\mathrm{Fe}$ into garnet as strongly as does $\alpha$, so $\beta$ is not initially Mg-enriched, and the completion of the $\alpha-\beta$ transition is not postponed relative to Fo89. The net effect of postponing onset but not completion is to concentrate the transition into a narrower range of depths, decreasing the depth-extent of the wave-speed increase by some $6 \mathrm{~km}$ relative to that expected for Fo89 $(>10 \mathrm{~km})$, in better agreement with seismic ${ }^{6}$ estimates $(<5 \mathrm{~km})$.

Furthermore, mineral wave-speeds themselves also vary with composition. Wave-speed increases across the $\alpha-\beta$ transition in isolated Fo89 can be measured in the laboratory, extrapolated to mantle conditions, and scaled for a mantle model which is about $60 \%$ olivine by volume. Although subject to remaining uncertainties $^{7}$ in the pressure- and temperaturedependence of mineral wave-speeds, some such analyses ${ }^{8}$ yield increases whose magnitudes are rather larger than those inferred for the $410-\mathrm{km}$ seismic discontinuity. In pyrolite, on the other hand, the $\mathrm{Mg}$ -

\title{
Palaeontology
}

\section{The eyes have it}

Life on land is so challenging that many land vertebrates have taken the plunge and gone back to the sea. From porpoises to placodonts, pliosaurs to pinnipeds, the examples are legion. But life in the sea poses a unique problem for a returning land vertebrate - salt.

A marine vertebrate with a terrestrial ancestry has body fluids that are much less salty than sea water, so an unprotected vertebrate immersed in the sea runs the risk of dehydration. Water can be replaced by drinking sea water. This raises the saltiness of the body with respect to the sea, so there can be no net gain of water unless the salts are excreted in a solution at least as concentrated as that of sea water. The kidneys of marine reptiles, such as turtles, do not have this concentrating power: without other methods of voiding excess salt, a marine reptile cannot eat salty food or drink sea water without becoming dehydrated in the midst of plenty.

Marine life is simply unliveable unless an animal solves the salt problem. This 200-millimetre-long, 110-million-year-old fossil marine turtle, described by Ren Hirayama on page 705 of this issue (Nature 392, 705-708; 1998), has taken this lesson on board. The creature, which comes from

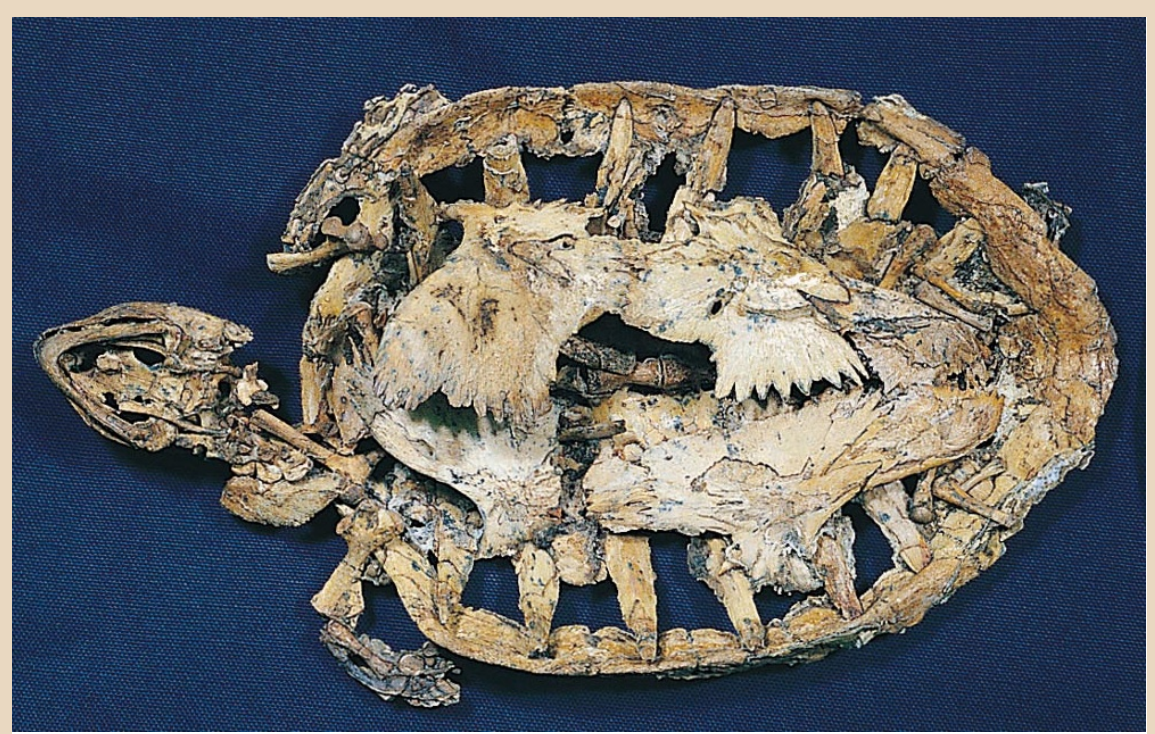

the Lower Cretaceous Santana Formation of north-east Brazil, extends the fossil record of marine turtles back ten million years. The turtle is primitive in the sense that the bones in its wrists, ankles and digits have not become consolidated into rigid paddles. In other words, its feet would have looked more like those of freshwater terrapins than fully seagoing turtles.

Its salt-excreting arrangements were, in contrast, far less haphazard. Marine turtles have lachrymal glands (each one larger, in some cases, than the brain) modified to excrete a concentrated salt solution. The skull of the Santana turtle shows evidence that it had enormous salt glands around the eyes. In which case, the evolution of salt-excreting glands preceded that of rigid paddles. These salt glands were the turtles' passport back to the sea.

Henry Gee 